PROBLEMS

OF EDUCATION

IN THE $21^{\text {st }}$ CENTURY

Vol. 77, No. 1, 2019

\section{SYNERGETIC EFFECTS MANIFESTATION BY FOUNDING COMPLEXES DEPLOYMENT OF MATHEMATICAL TASKS ON THE CHESSBOARD}

\author{
Svetlana N. Dvoryatkina \\ Bunin Yelets State University, Russia \\ E-mail: sobdvor@yelets.lipetsk.ru
}

\begin{abstract}
The urgency of the problem is due to the insufficient development of theoretical, content-technological and methodological aspects of the integration of mathematical knowledge and chess skills. The manifestations of synergistic effects arising in the course of the integration of mathematical and game chess activity, while resolving uncertainties on the chessboard due to the activation of key components of creativity, have not been sufficiently studied. The synergistic effect of the integration of mathematical knowledge and chess skills is considered from the perspective of the components of theoretical thinking and is evaluated by the student's creative choice in the search for alternative solutions. The purpose of the study is to describe and evaluate the manifestations of the structural components of the creative effect in the context of the introduction of funded complexes of mathematical problems on a chessboard. The hypothesis of the research: theoretical analysis of educational material, reflection and an internal plan of action as comparable processes for solving mathematical problems in terms of implementation substantiate complexes will lead to manifestations of arguments-heuristic, intellectual and logical and motivational components of creative activity.

The research assumed the measurement of the manifestations of the structural components of creativity in the context of the introduction of funding complexes of mathematical problems on a chessboard. In the process of identifying the structural components of creativity, psychodiagnostic diagnostics tools were developed for intellectual-heuristic, intellectual-logical, motivational and reflexive aspects, comparative diagnostics were carried out for all structural components, the average level and integral indicators in the control and experimental groups were calculated.

The formation of creativity was carried out by developing the ability to argue in the process of solving multi-stage mathematical problems on the chessboard. The choice of cause-and-effect relationships stimulated creative independence and reflexivity, enhancing the manifestations of the synergistic effect. On the basis of internal cognitive consonance, non-standard original ideas were identified; by overcoming emotional instability, the logical component of argumentation was strengthened.
\end{abstract}


Svetlana N. DVORYATKINA, Vladimir S. KARAPETYAN, Alla M. DALLAKYAN, Svetlana A. ROZANOVA, Eugeny I. SMIRNOV. Synergetic effects manifestation by founding complexes deployment of mathematical tasks on the chessboard

PROBLEMS

OF EDUCATION

IN THE $21^{\text {st }}$ CENTURY

Vol. 77, No. 1, 2019

The results of the research revealed a positive trend in the key components of creativity in the context of the introduction of a chess game in the process of learning mathematics. In the future, it is possible to upgrade the methodological educational material for the system of inclusive mathematical education.

Keywords: synergistic effect, creativity, fundamental problem complexes, uncertainty resolution, mathematical problems on a chessboard.

\section{Introduction}

Issues related to the research of a complex phenomena of "creativity" are given considerable attention in scientific literature. There is a constant search for new methods, means and forms of training that make it possible to actualize the creative potential of students. A new and effective mechanism in this direction is "chess mathematics". The "chess effect" hypothesis has stimulated numerous research projects around the world. Most researches focused on the impact of chess on academic success in mathematics. The integration of chess training with mathematical education was studied in order to develop logical thinking and intellectual abilities of students (Brestel, 2011; Geek, 2009, 2010; Dvoryatkina \& Loskutov, 2016; Karapetyan, 2014; Poloudin, 2017; Sukhin, 2012). In the works (Karapetyan, Mirzakhanyan \& Gevorgyan, 2016; Karapetyan \& Gevorgyan, 2017) the interrelation between the determination of the expediency of the choice of chess moves with typical manifestations of cognitive dissonance and consonance, which naturally arise in the process of argumentation. The psychological phenomenon of cognitive dissonance and consonance in the field of argumentation during the game of chess is transformed into the appropriate orientation situations. The results of emotionallogical comparison with logical and internal conflicts are considered. This is evidenced by the subsequent choice, adequately or inadequately expressed in the emotional and behavioral manifestations of the players. European researchers (Burgoyne \& Sala, 2016; Sala \& Gobet, 2016; Sala, Foley \& Gobet, 2017) found that chess training improves mathematical abilities in primary and basic general education students.

However, many years of professional practice of teachers and coaches in chess shows that a chess game, in addition to its impact on intellectual development, promotes creative activity and the development of students' reflexive abilities. The chess fantasy expands the player's understanding of their capabilities in the course of gaming activities and contributes to the choice of the correct move in the position. In psychology, creative activity in this context is not sufficiently studied. Mathematical problems on the chessboard belong to the class of unsolvable algorithms, an algorithm that consists in the complete search of all variants, that is, to the class of "NP-complete problems" (non-deterministic polynomials) in the theory of algorithms (McConnell, 2001)

Thus, mathematical problems on the chessboard are traditional creative problems, because, firstly, the search for their solutions is carried out in an infinite, unlimited extent; secondly, a variety of goals leads to an unlimited number of possible decisions. So, the skill of setting goals or targets in the process of solving mathematical problems on a chessboard can contribute to the development of creative thinking of a student and to the reflection of their own choice. Description of the manifestations of synergetic effects and purposeful activity of students helps to determine the essence of synergy in the context of creative activity and to estimate the value of synergetic effects from the integration of mathematical knowledge and the ability to choose a solution in a variety of alternatives.

All that was noted above determined the following:

- the problem of the research, which consists of the search for theoretical and methodological provisions and didactic mechanisms of integration of mathematical knowledge and chess skills to choose a solution in a plurality of alternatives to chess game to update the creativity of students. 
Svetlana N. DVORYATKINA, Vladimir S. KARAPETYAN, Alla M. DALLAKYAN, Svetlana A. ROZANOVA, Eugeny I. SMIRNOV. Synergetic effects manifestation by founding complexes deployment of mathematical tasks on the chessboard

PROBLEMS

OF EDUCATION

IN THE $21^{\text {st }}$ CENTURY

Vol. 77 , No. 1, 2019

- the aim of the research, that is to describe and assess the manifestations of the structural components of the creative effect in the introduction of ponderous complexes of mathematical problems on a chessboard;

- the hypothesis of the research: the theoretical analysis of the educational material, reflection and internal action plan as comparable processes of solving mathematical problems in the conditions of implementation of foundation complexes will lead to the manifestations of reasoned-heuristic, intellectual-logical and motivational components of creative activity.

\section{Methodology of Research}

\section{General Background}

The research of the problem was carried out in three stages:

- at the first stage, a theoretical analysis of synergetic approach and founding methodology, dissertation works on the problem, as well as theory and methodology of pedagogical research; the problem, purpose, and research methods are set out. So, the experimental research plan is worked out;

- at the second stage, a draft four-stage funding complex of tasks on a chessboard was presented, with the updating of synergy attributes (multiplicity of goal setting, resolution of uncertainty) and manifestation of the creative effect; An integrated methodological complex has been developed, including diagnostics of the components of creativity (argued-heuristic, intellectual-logical, motivational, reflexive). An experimental work has been carried out; the conclusions obtained during the experimental work have been analyzed, tested and clarified;

- in the third stage, the experimental work has been completed, theoretical and practical conclusions have been refined, statistical processing of the data has been carried out, obtained results have been summarized and systematized.

Experimental base of the research has been the Scientific Research Institute of Chess of Armenian State Pedagogical University named after Khachatur Abovyan, Chess Academy of Armenia, Schools No. 57, 194, 33 in Yerevan, secondary school No.5 in Yelets, Lipetsk Region.

Students at the age of 9 to 16 years took part in the formative experiment. For the students of the experimental group $\left(n_{1}=180\right)$, the methodology of teaching mathematics was based on the introduction of chess in the educational process. In the control group $\left(\mathrm{n}_{2}=180\right)$, the teaching of mathematics was taught using traditional teaching methods.

When selecting control and experimental groups, the principle of creating representative groups was dominant, which is important for statistical processing of the research results. In particular:

1. For each age or class, an equal number of boys and girls were selected with an average level of achievement in mathematics and chess discipline;

2. Considered the same motivational figure, expressed an interest in mathematics and chess;

3. The choice of teachers in these disciplines was carried out on the principle of the same rating (pedagogical knowledge and skills);

4. The factor of emotional stability and extroversion of the student was taken into account (according to G. Eysenck).

\section{Instrument and Procedures}

The quantitative assessment of the synergistic effect of a trainees' creative activity in the context of the integration of chess education into mathematical education includes the 
Svetlana N. DVORYATKINA, Vladimir S. KARAPETYAN, Alla M. DALLAKYAN, Svetlana A. ROZANOVA, Eugeny I. SMIRNOV. Synergetic effects manifestation by founding complexes deployment of mathematical tasks on the chessboard

PROBLEMS

OF EDUCATION

IN THE $21^{\text {st }}$ CENTURY

Vol. 77, No. 1, 2019

development of a complex methodological complex including the diagnosis of the following components of creativity: a reasoned heuristic, intellectual and logical, motivational and reflexive. It is noteworthy that psychologists use various chess problems with non-standard figures on non-standard boards to diagnose creativity (Bogoyavlenskaya \& Nizovtsova, 2017). The unusual situation, according to the researchers, should smooth out the differences between experienced players and those who could not play chess before.

The development of personality is impossible to imagine without the presence of situations of intellectual tension in the conditions of uncertainty and lack of future activities prediction, opportunities to overcome the problem areas that arise in integration of mathematical education and chess playing. The presence of such problem areas and situations of overcoming is directly related to the development of complex knowledge and is an important attribute of qualitative changes in the development of personality.

The choice of criteria for creativity is justified by the connection of theoretical thinking with the development of an internal plan of action, especially in divergent thinking, which is typical in the process of solving mathematical problems on a chessboard. At the same time, with the resolution of uncertainty on a chessboard in the conditions of a plurality of alternatives, creativity appears, serving as the result of comparing different ways of solving problems in the internal plan of action. The synergistic effect is considered in the context of the development of a theoretical type of thinking according to V.V. Davydov (1995), taking into account the activation of the components of theoretical analysis, reflection and internal action plan. In this context, the psychological basis for the implementation of funding complexes of mathematical tasks on a chessboard are:

1. Theory of the development of theoretical thinking by V.V. Davydov;

2. Psychological basis for the development of the ability of an internal action plan.

On the basis of theoretical analysis and generalization of scientific research in the studied direction, the following criteria for the manifestation of creative effect have been identified: intellectual-heuristic (Karapetyan, Gevorgyan, 2017); intellectual-logical (Sala, Foley, Gobet, 2017; Dvoryatkina, Loskutov, 2016); motivational (Rozanova, Karapetyan, Smirnov and others, 2015); reflexive (Hartkens, 2017), and also search of corresponding diagnostics techniques allowing to fix this quality was carried out (Table 1).

Table 1. Components, criteria of creativity and diagnostic means.

\begin{tabular}{|c|c|c|}
\hline $\begin{array}{l}\text { Structure of crea- } \\
\text { tivity, } \\
\text { key components }\end{array}$ & $\begin{array}{l}\text { Diagnostic characteristics of creativity } \\
\text { (criteria for synergy manifestation) }\end{array}$ & Diagnostic Means \\
\hline $\begin{array}{l}\text { Argumentative-heu- } \\
\text { ristic }\end{array}$ & $\begin{array}{l}\text { - ability to produce a large number of ideas based on } \\
\text { internal cognitive consonance; } \\
\text { - ability to overcome emotional instability (disso- } \\
\text { nance) with the strengthening of the logical compo- } \\
\text { nent of argumentation; } \\
\text { - ability to produce unusual, non-standard ideas } \\
\text { (originality) }\end{array}$ & $\begin{array}{l}\text { methodology of PARLA with the purpose } \\
\text { of determining the validity of the course of } \\
\text { problems solving on the following chain: } \\
\text { problem-action-result-teaching/learning } \\
\text { the usage of experience in solving of } \\
\text { similar tasks }\end{array}$ \\
\hline Intellectual-logical & $\begin{array}{l}\text { - ability to analyze and synthesize; } \\
\text { - divergence and associativity of thinking; } \\
\text { - flexibility and fluency of mental operations; }\end{array}$ & $\begin{array}{l}\text { test of the structure of intelligence of } R \text {. } \\
\text { Amtkhauer; }\end{array}$ \\
\hline Motivational & $\begin{array}{l}\text { - self-determination and self-improvement, creative } \\
\text { self-realization; } \\
\text { - cognitive activity, motivation to achievement. }\end{array}$ & $\begin{array}{l}\text { methodology of Ch. D. Spielberger (the } \\
\text { modification of A. D. Andreev for Russia) }\end{array}$ \\
\hline Reflexive & $\begin{array}{l}\text {-self-evaluation of the person; } \\
\text {-reflexion. }\end{array}$ & $\begin{array}{l}\text { methodology for research of self-evalua- } \\
\text { tion of the person by S. A. Budassey; } \\
\text { methodology for diagnosing the level of } \\
\text { reflexivity by A. B. Karpov }\end{array}$ \\
\hline
\end{tabular}


Svetlana N. DVORYATKINA, Vladimir S. KARAPETYAN, Alla M. DALLAKYAN, Svetlana A. ROZANOVA, Eugeny I. SMIRNOV. Synergetic effects manifestation by founding complexes deployment of mathematical tasks on the chessboard

OF EDUCATION

IN THE $21^{\text {st }}$ CENTURY Vol. 77, No. 1, 2019

12

The results of the interview with PARLA method and the analysis of the game of chess revealed that the usefulness of the learned move does not correspond to its future implementation. The PARLA method was also used in the process of argumentation with the aim of:

a) Combining or correlating the data of the trainer and the school psychologist with the results obtained with PARLA method;

b) Consideration of chess game from the beginning to the end in chain context: "problem - action - result - training - implementation";

c) Clarification of those personal qualities of chess players, which are manifested especially in the chain of "teaching- implementation".

In addition to the above-mentioned, during the interview we were interested in how the students learned to approve their own moves and how to implement them. It turned out that application of PARLA method is more expedient in the course of the interview, after the joint work of the trainer and the school psychologist, as the number of new actions, which are previously unfamiliar to the child (training and implementation), increases.

Many-stage mathematical assignments for the purpose of forming creative activity of students were previously used by the Polish mathematician schools with in-depth study of mathematics (Klyakla, 2003), Russian researchers (Smirnov, Secovanov \& Mironkin, 2014) in the teaching of fractal geometry etc. According to the mentioned authors, the introduction of innovative teaching means in the form of multi-stage mathematical assignments as part of the substantiating complexes ensures the formation of creativity, including: the development of intellectual operations and reflexive abilities, convergent and divergent thinking, tolerance to innovation, the development of skills to predict the results of mathematical activity. Each cycle is a logical chain of tasks connected with a single supporting idea, with the gradual accumulation and complication of information on the implementation of that idea. It will be illustrated the technological chain of solving mathematical tasks on the chessboard with the actualization of synergy attributes (the variety of goal setting, the generalized construct of the "problem zone" of mathematics, the dialogue of the mathematical, information, humanitarian and natural science cultures) and the manifestation of creative synergetic effect.

The motivational stage is manifested in the expression of the value and personal characteristics of cognitive and creative activity of the learners in mastering the standards and models of phenomenology of visual-intuitive modeling of applied mathematical tasks. In this stage, it will be expedient to offer students by solving the most common geometric tasks - the tasks of cutting a chessboard, allowing to obtain geometric forms of different complexity and accordingly, consciously (by choice, rather than pattern) solve geometric tasks for symmetry, parallel lines, coordinate system, equality of figures, the properties of a square, a triangle etc. The main method for solving tasks of this class will be a problem situation or a problematic dialogue that establishes the possibility of formulating the ultimate goal for finding the potential for the choice of solutions.

1. The legend about four diamonds. One oriental lord was a very good chess player, that in his entire life he lost only four games. In honor of his winners, he ordered four pieces of diamond to be inserted in the board, one for each field, where he was put mat (Figure 1, where knights are depicted instead of diamonds). After the death of the lord, his son, a weak player and cruel despot, decided to take revenge on them. He ordered the players to cut the board into identical pieces, so that in each of them there was one diamond. It is assumed that the cuts pass only along the boundaries between the verticals and horizontal contours of the board.

Decision. One of the correct solutions is shown in Figure 1.

Having four knights in different fields of the board, we can get many tasks connected with cutting. The interest is not only finding one necessary cut, but also counting the number of all methods to cut the board into four identical parts containing one knight each. It is noted that the greatest number of solutions (800) is the problem with the arrangement of the knights in the corners of the board. 


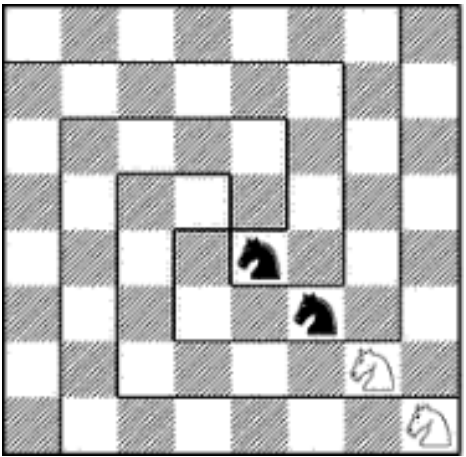

Figure 1. The legend about four diamonds.

2. The paradox of cutting the chessboard. Cut the chessboard into four parts, as shown in Picture 3, and draw a rectangle from them (Figure 2). The chessboard consists of 64 cells, but the resulting rectangle is made up of 65. Question: where was one extra field from?

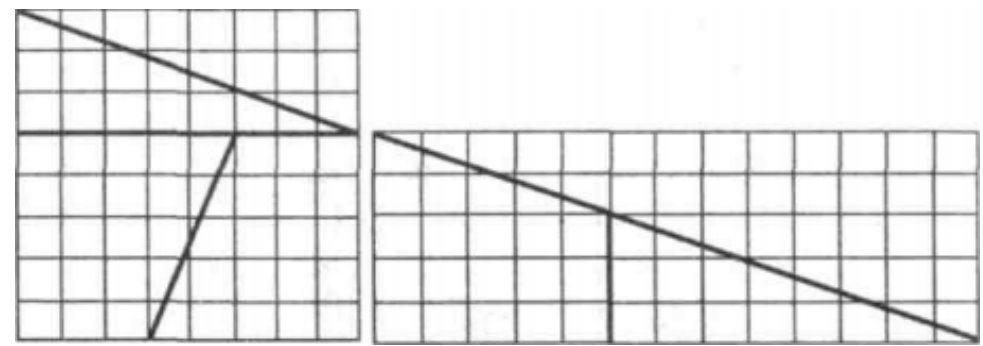

Figure 2. The paradox of cutting the chessboard.

The solution of paradox lies in the drawing fact is not entirely accurate. If you make it more accurate, you can see a barely noticeable parallelogram. Its area is equal to the area of the extra cell.

3. The Proof of Pythagoras theorem on the chessboard. Cut the board as shown in Figure 3. The board is divided into a square and four equal right-angled triangles. In both cases, the areas of the triangles are equal, which means that the areas of the remaining figures are also equal. Since a large square is built on the hypotenuse of a right-angled triangle, and small ones are on its cathete, hence the square of the hypotenuse is equal to the sum of the squares of the cathete.
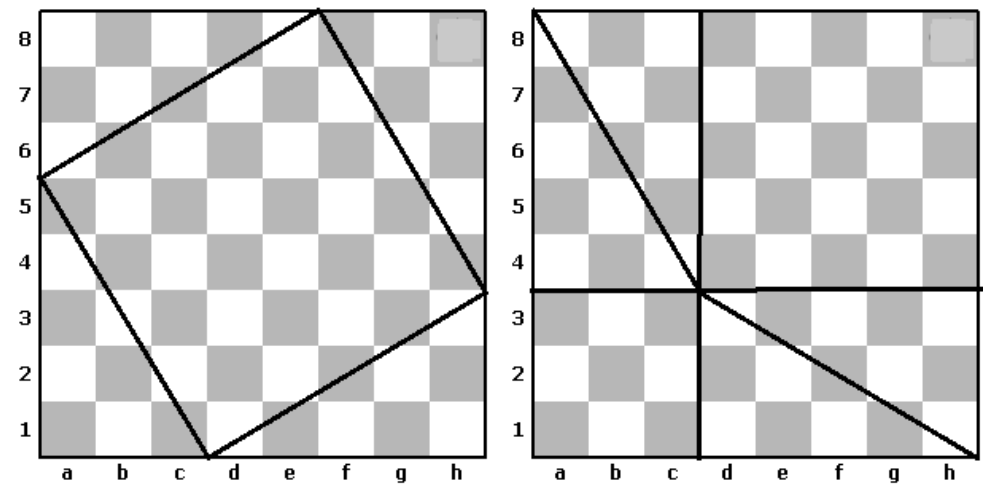

Figure 3. Theorem of Pythagoras on the chessboard. 
Svetlana N. DVORYATKINA, Vladimir S. KARAPETYAN, Alla M. DALLAKYAN, Svetlana A. ROZANOVA, Eugeny I. SMIRNOV. Synergetic effects manifestation by founding complexes deployment of mathematical tasks on the chessboard

OF EDUCAT

IN THE $21^{\text {st }}$ CENTURY Vol. 77 , No. 1, 2019

4. How many cuts are needed on the board to cross all of its fields?

The stage of process-activity is manifested in the design and organization of procedures for mastering innovative manifestations of the essence of a mathematical construct on the basis of actualizing the techniques of creative cognitive self-activity. To improve the effectiveness of goal-setting at the stage of learning activity of students organizing it is necessary to develop the creativity of thinking to optimally overcome the situation of uncertainty in the conditions of alternatives variety. It forms such information contexts where the development of goal-setting is carried out in the logic, posing and solving both mathematical and chess problems.

At this stage, tasks can be recommended that illustrate the unusual geometry of the board and the unexpected properties of the figures. For example, according to Euclidean geometry, the shortest distance between two points is a straight line. However, in chess this is not always the same. On this property, such techniques as "repulsion by the shoulder" and others are based. One of the most famous chess e'tudes by R. Reti can illustrate this property (Figure 4).

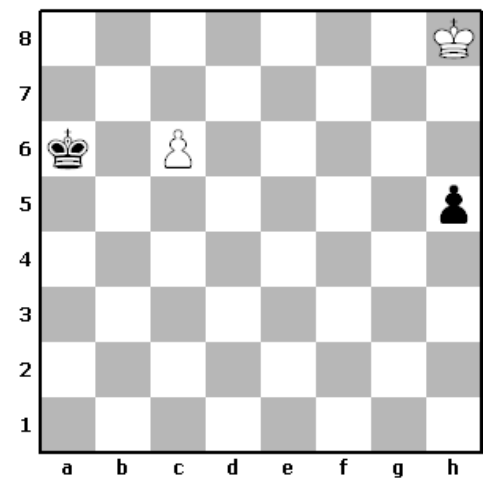

Figure 4. E'tude by Rikhard Reti.

It seems absolutely incredible that in this position the white king is able to cope with a black pawn. However, this becomes possible if he follows her not by the usual straight line, but by the "royal" one. To the field of $\mathrm{h} 2$, the white king can reach in different ways. The route of h8-g7-f6-e5-f4-g3-h2 is equal in length, i.e. in number of turns to the route of h8-h7-h6-h5h4-h3-h2. On the chessboard, the two cathete turned out to be equal to the hypotenuse. The method of solution proposed by Ye. Ignatiev (2018), will be innovative and unexpected, for the derivation of algebraic formulas with the help of the chessboard. For example, to prove the equality:
a); $1+2+\ldots+n=\frac{n(n+1)}{2}$;
b). $8(1+2+\ldots+n)+1=(2 n+1)^{2}$.

The proof of equality a): let's find the sum of the $\mathrm{n}$ of the first natural numbers "by the method of the chessboard". To do this, we black out all the fields of the first vertical on the board $(\mathrm{n}+1) \times \mathrm{n}$ (Pic. 5, where $\mathrm{n}=8)$, all the fields of the second vertical (except for the top), the third vertical (except for the two tops), etc., finally - the bottom field of the n-th vertical. As a result, white and black fields on the board will be equally divided, especially $1+2+\ldots+n$. Since the board area is $n(n+1)$, we get $2(1+2+\ldots+n)=n(n+1)$.

The control-corrective stage is manifested in monitoring and diagnostics of procedures for measuring the state and expansion of experience, in manifesting of synergetic effects and characteristics of learners' personal qualities, in determining and optimizing technological procedures and the content of mathematical education.

At this stage, it is possible to recommend assignments with different variations of the conditions and data of the tasks, an estimate of the choice of optimal method for solving the problem, tasks with incomplete data etc. 
Svetlana N. DVORYATKINA, Vladimir S. KARAPETYAN, Alla M. DALLAKYAN, Svetlana A. ROZANOVA, Eugeny I. SMIRNOV. Synergetic effects manifestation by founding complexes deployment of mathematical tasks on the chessboard

Task. How many ways are there to place 8 rooks on the chessboard so that neither of 15 them can take the other?
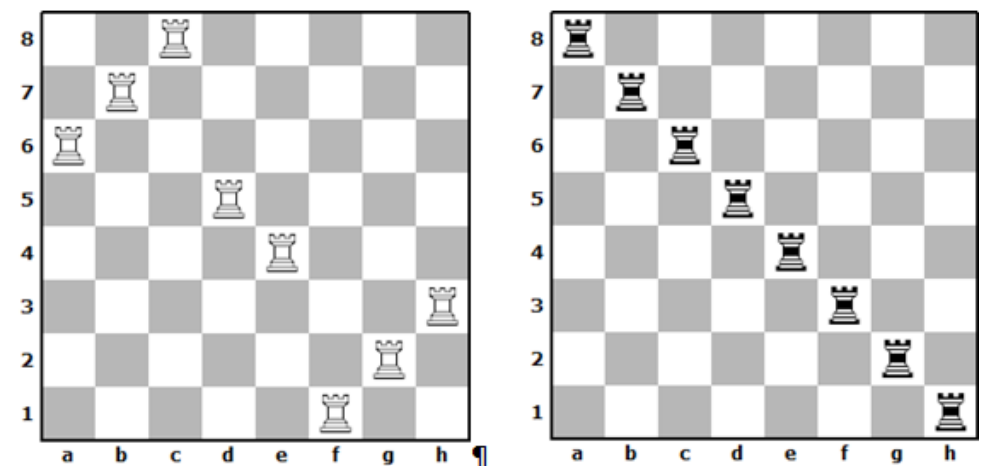

Figure 5. To place 8 rooks on the chessboard.

In "mathematical" presentation the task can be formulated in several ways : "Fill the 8 $\times 8$ matrix with zeros and ones so that the sum of all elements of the matrix is $8 \times 8$, the sum of elements in any column, row or diagonal array did not exceed one "; or to obtain other variants of its solution by means of following transformations: by turning the chessboard by 90 , 180, 270 degrees , respectively; axial symmetry with respect to main diagonals: horizontal and vertical axes of symmetry of the chessboard. As a result, we obtain equivalence classes of possible arrangements that pass into each other, that is, combinatorial orbits. The ultimate goal set before determining this task can also be formulated in several variants:

1. Construct one solution of the task;

2. Analytically prove that the solution exists;

3. Determine the possible number of solutions;

4. Construct all possible solutions.

To solve a similar problem, learners can use the following types of solutions: combinatorial method, graph theory, the method of mathematical induction, and also the arithmetic progression, which was successfully used by the French mathematician E. Luke. Mastering a wide arsenal of methods for solving the mathematical tasks, students are flexible in the formulation and selection of goals, maximum self-independence and, as a result, the ability of self-realization. The most productive at this stage will be combinatorial tasks on the chessboard (Marcuson, 1989).

The general-transformative stage is characterized by the content and characteristics of innovations transfer into the mass practice of school mathematics mastering, the integration of the individual and the social in the design of innovative mathematical constructs, exchange of information and verification of the innovative activity of students. In this stage, it is also possible to form several goals. The main efforts of the learners are concentrated on a multipurpose approach. There is a strong correlation between the capacity for goal-setting and reflection, which provides a productive analysis of the goal-setting process; creative thinking, which allows the effective usage of creative goal-setting strategies; motivation, which activates and regulates the self-development of the learners as an individual of goal-setting.

It is possible to offer research tasks to junior schoolchildren on modern scientific problems, for example, on combinatorics: architectural combinatorics (studying the problems of architectural shaping on the basis of various combinations), combinatorics in programming (research and study of various combinatorial algorithms for EBM), combinatorics of orbits (obtaining new solutions of combinatorial tasks by converting and separating classes of equivalence), etc. 
Svetlana N. DVORYATKINA, Vladimir S. KARAPETYAN, Alla M. DALLAKYAN, Svetlana A. ROZANOVA, Eugeny I. SMIRNOV. Synergetic effects manifestation by founding complexes deployment of mathematical tasks on the chessboard

OF EDUCATION

IN THE $21^{\text {st }}$ CENTURY

Vol. 77 , No. 1, 2019

16

\section{Data Analysis}

For the convenience of the comparative analysis, all diagnostic data were distributed according to levels - low, average, high. On the basis of the frequency distribution of the experimented subjects by levels, the average level indicator (ALI) of each quality was calculated on a three-level scale by the formula: ${ }_{A L I}=\frac{a+2 b+3 c}{100}$ where a, b, c is the percentage of the number of experimented subjects with low (a), average (b), high (c) levels of developmental characteristics, according to the used diagnostic methodologies.

\section{Results of Research}

The hypothesis of a study on the promotion of funding complexes of mathematical problems on a chessboard to the manifestations of heuristic, intellectual, logical and motivational components of creative activity was experimentally confirmed.

Table 2 presents the comparative diagnostic data for all structural components and their characteristic properties, including the indicator of average level and the integral indicator in the control and experimental groups.

Table 2. The diagnostics for creative effect.

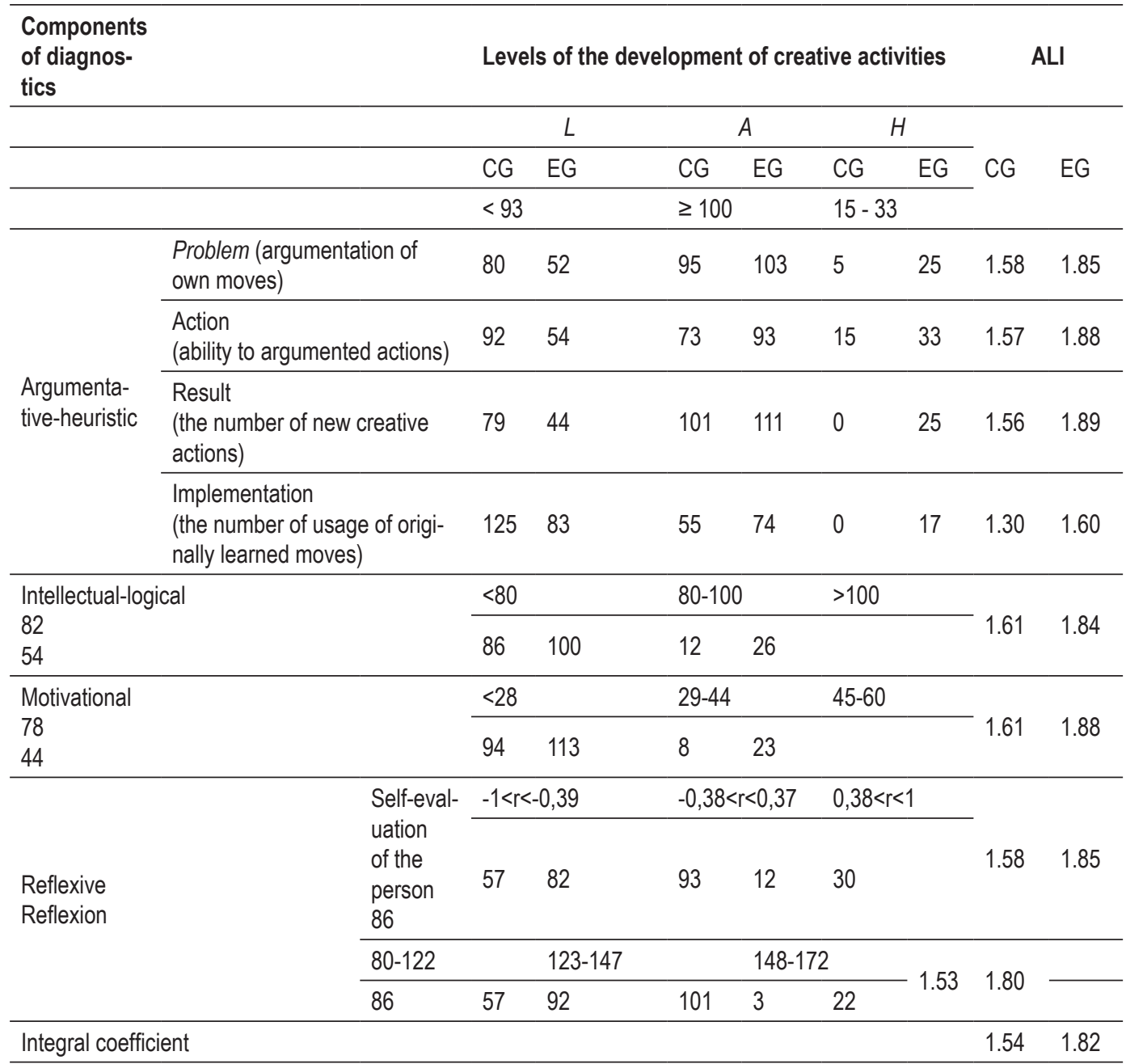


Svetlana N. DVORYATKINA, Vladimir S. KARAPETYAN, Alla M. DALLAKYAN, Svetlana A. ROZANOVA, Eugeny I. SMIRNOV. Synergetic effects manifestation by founding complexes deployment of mathematical tasks on the chessboard

\author{
PROBLEMS \\ OF EDUCATION \\ IN THE $21^{\text {st }}$ CENTURY \\ Vol. 77, No. 1, 2019
}

A statistics using Pearson's criterion has been established of the level of creative

activity development of students for all components in the control and experimental groups (for the absolute frequencies of the trait). The main tested hypothesis, which is that there is no difference in the level of the development of the cognitive sphere for individual components between the control and experimental groups, was rejected $\left(\chi^{2}=7.26, p<.05\right.$ for the intellectual-heuristic component, $\chi^{2}=6.82, p<0.05$ for the intellectual-logical component, $\chi^{2}=11.22, p<.05$ for the motivational component, $\chi^{2}=6.57 ; \chi^{2}=6.30, p<.05$ for the reflexive component).

Positive dynamics in the change in the ALI of trainees, characterizing the level of cognitive processes development for the selected components (Figure 6), as well as significant changes in the integral indicator (positive dynamics by $28 \%$ ) have been revealed. All this made it possible to reliably assert that the introduction of chess in teaching mathematics had a positive impact on the level of development of all diagnosed indicators.

The correlation analysis of the obtained indicators of the control and experimental groups for all levels of development of creative activity (low, medium, high) revealed the presence of a certain dependence, in particular:

- with a low level of development of creative activity - the correlation coefficient between the control and experimental groups is 0.9550 ;

- with an average level of development of creative activity - the correlation coefficient between the control and experimental groups is 0.9505 ;

- with a high level of development of creative activity - the correlation coefficient between the control and experimental groups is equal to 0.8122 .

A comparative analysis of correlations shows:

- the effectiveness of the selection of representative groups based on the principle of homogeneity;

- the effectiveness of the implementation of funding complexes of mathematical problems on a chessboard. The introduction of substantive constructs contributes to the development of components of theoretical thinking: 1) the ability to theoretical analysis of the problem, tasks; 2) reflection; 3) internal action plan. Each component of theoretical thinking contains certain elements of creativity. Thus, the relationship between theoretical thinking and creativity has been experimentally proven. 
Svetlana N. DVORYATKINA, Vladimir S. KARAPETYAN, Alla M. DALLAKYAN, Svetlana A. ROZANOVA, Eugeny I. SMIRNOV. Synergetic effects manifestation by founding complexes deployment of mathematical tasks on the chessboard

OF EDUCAT IN THE $21^{\text {st }}$ CENTURY Vol. 77, No. 1, 2019

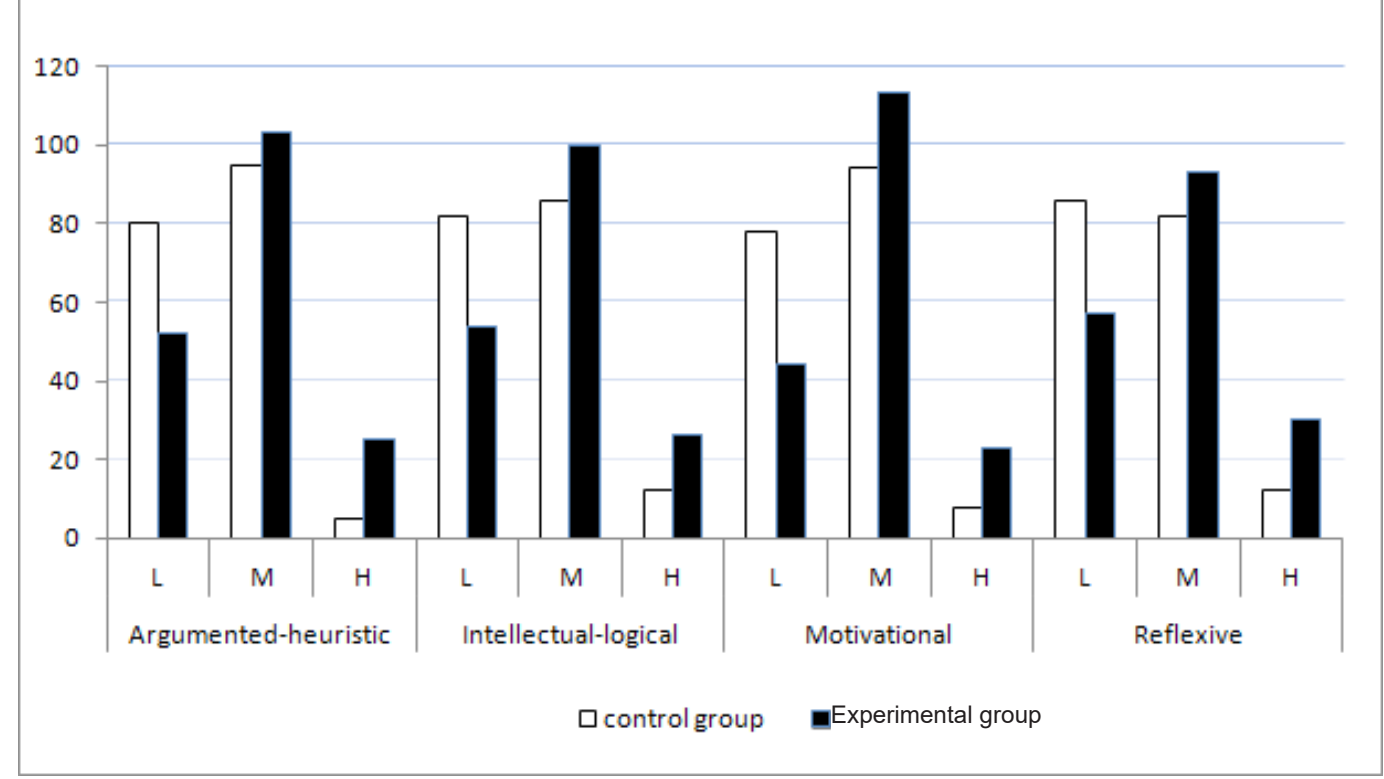

Figure 6. Visual representation of empirical data.

\section{Discussion}

The problem of the formation of creativity in the process of mathematical education was solved by researchers before. However, its decision was based on the development of intellectual operations and reflexive abilities, the formation of tolerance for innovation and the ability to predict the results of mathematical activity. The didactic mechanism, or the algorithm of actions leading to the creativity of thinking and reflection of one's own decisions, was absent in the scientific and methodological literature. The present research not only proposes a new didactic mechanism for the actualization of creativity, but also involves the measurement of the manifestations of the structural components of creativity through the introduction of funded sets of mathematical problems on a chessboard. In the process of identifying the structural components of creativity, psychodiagnostic diagnostics tools of intellectual-heuristic, intellectual-logical, motivational and reflexive aspects were developed, comparative diagnostics were carried out for all structural components.

The formation of creativity was carried out by developing the ability to argue in the process of solving multi-stage mathematical problems on the chessboard.

Argumentation of solutions to mathematical tasks or moves on the chessboard stimulates not only creative independence, but also the activity of structural and functional components of synergy. In particular, non-standard original ideas are revealed based on the internal cognitive consonance; by overcoming emotional instability (cognitive dissonance), the logical component of the argumentation is strengthened.

A deeper study of the psychological mechanisms of argumentation in the process of integrating chess in mathematical education will allow to expand the possibilities for the development of personal and creative potential, self-organization and self-regulation. Due to overcoming cognitive dissonance in solving mathematical problems on the chessboard, the divergence of thinking is formed, the reflexion of own judgments is manifested and the argumentational actions are selected.

Theoretically justified and experimentally investigated is also the assistance of funding complexes of mathematical problems on a chessboard to solving these same problems in 
Svetlana N. DVORYATKINA, Vladimir S. KARAPETYAN, Alla M. DALLAKYAN, Svetlana A. ROZANOVA, Eugeny I. SMIRNOV. Synergetic effects manifestation by founding complexes deployment of mathematical tasks on the chessboard

\author{
PROBLEMS \\ OF EDUCATION \\ IN THE $21^{\text {st }}$ CENTURY \\ Vol. 77, No. 1, 2019
}

the context of the concept of developmental education, which is comparable to the logic of

manifestations of synergistic effects. The established relationship of creativity with the ability to perform actions in the internal plan opens up broad prospects for further understanding the concept of personal development, the study of issues related to the development of theoretical thinking.

\title{
Conclusions
}

The modern concept of a student's personality development is based on the actualization of such personal qualities and abilities as self-organization and self-expression, self-esteem and reflection. The integration of the elements of theoretical thinking and creativity, emotional and volitional manifestations, characteristic of a chess game, the harmonious design of this synergy can be a psychological mechanism not only of the intellectual, social and personal, but also the creative development of the child.

The effective development of creativity is possible with the consistent organization of the educational process by including multi-stage mathematical assignments on the chessboard as part of founding complexes. Each cycle is a logical chain of tasks connected with a single supporting idea, with the gradual accumulation and complication of information on the implementation of the idea.

In order to test the effectiveness of the proposed methodology, multidimensional qualimetric tools were developed, including diagnostics of the main components of the creative sphere (argued-heuristic, intellectual-logical, motivational and reflexive). The obtained statistical results allow us to conclude about the effectiveness of the presented didactic tools.

In the future, it is possible to modernize the methodological teaching material for a system of inclusive mathematical education based on a chess game. The potential of chess, as an intellectual sport with small motor activity of individuals, combined with digital and mathematical education, will provide favorable conditions for improving the inclusive process. The synergy of inclusive mathematical, digital teaching and chess as an innovative multifactorial tool in the complex system of rehabilitation of persons with disabilities in Russia can bring significant changes. In particular, it will increase the degree of formation of educational-cognitive, informative, communicative competencies of learners, actualize the intellectual activity and creative potential of students with disabilities, and give an opportunity to get a high-quality education in accordance with modern federal state educational standards.

\section{Acknowledgements}

The research was supported by Russian Science Foundation (project No.16-18-10304).

\section{References}

Bogoyavlenskaya, D. B., \& Nizovtsova, A. N. (2017). On a problem of relationships of general, special and creative abilities on example of mathematical giftedness. Psychology. Journal of the Higher School of Economic, 14 (2), 277-297. https://doi.org/10.17323/1813-8918-2017-2-277-297.

Burgoyne, A., Sala, G., Gobe, F., Macnamara, B., Campitelli, G., \& Hambrick, D. (2016). The relationship between cognitive ability and chess skill: A comprehensive meta-analysis. Intelligence, 59, 72-83. https://doi. org/10.1016/j.intell.2016.08.002.

Brestel, T. G. (2011). The development of imaginative and logical thinking of primary school children through teaching the game of chess. Elementary School Plus Before and After, 9, 81-82.

Gik, E.Ya. (2010). Mathematics and Chess. Moscow, Russia: Bureau Quantum.

Gik, E.Ya. (2009). Mathematics on a chessboard. From Euler and Gauss to the era of computer champions. Moscow, Russia: World encyclopedia. Avanta +: Astrel. 
Svetlana N. DVORYATKINA, Vladimir S. KARAPETYAN, Alla M. DALLAKYAN, Svetlana A. ROZANOVA, Eugeny I. SMIRNOV. Synergetic effects manifestation by founding complexes deployment of mathematical tasks on the chessboard

\section{PROBLEMS \\ OF EDUCATION \\ IN THE $21^{\text {st }}$ CENTURY Vol. 77, No. 1, 2019 \\ 20}

Davydov, V. V. (1995). O ponyatii razvivayushchego obucheniya [About the concept of developmental learning]. Tomsk, Russia: PEALING.

Dvoryatkina, S., \& Loskutov, S. (2016). Effective integration chess game the system of mathematics education of modern school. In: Proceedings of 5rd International Conference of mathematical education (pp. 37-42). Kazan, Republican Tatarstan.

Ignatiev, E. I. (2018). V carstve matematicheskoj smekalki [In the kingdom of mathematical ingenuity]. Moscow, Russia: AST.

Karapetyan, V. (2014). Target-oriented research of the strategic programmes on chess activities as specialized experimental platform for dynamic development of public education. In: Proceedings of the International Conference "Chess in Schools" (pp. 13-19). Yerevan, Armenia.

Karapetyan, V., \& Gevorgyan, S. (2017). Dissonance and consonance in argumentation sphere. The Bulletin of Irkutsk State University, 21, 21-27.

Karapetyan, V., Mirzakhanyan, R., \& Gevorgyan, S. (2016). Research as a deliberate chess activity software testing platform for professional dynamic development of the education sector. Management Studies, 4 (4), 161- 167. https://doi.org/10.17265/2328-2185/2016.04.003.

Klakla, M. (2003). Formation of the mathematics in Polish schools. Plock, Poland: Ritter.

Marcuson, R. (1989). Chess-board Combinatorics. Teaching Statistics, 11, 76-77.

McConnell, J. (2001). Analysis of Algorithms: An active learning approach. London, UK: Jones \& Bartlett Publishers.

Poloudin, V. (2017). Pilot Project: "Creative chess education of younger schoolchildren using electronic educational resource”. Primary Education, 5, 36-42. https://doi.org/10.12737/article_59f1b5c09 $7 \mathrm{~d} 043.84454630$.

Hartkens, J. (2018). Mathematische Reflexion in argumentativ geprägten Unterrichtsgesprächen [Mathematical reflection in argumentative class discussions]. Dortmunder Beiträge zur Entwicklung und Erforschung des Mathematikunterrichts, 29, 99-112. doi 10.1007/978-3-65818840-5_5.

Rozanova, S., Karapetyan, V., Smirnov, E., Mkrtchyan, M., Kuznetsova, T., Gevorgyan, P..,... de Sargsyan, A. (2015). The development of motivation to study mathematics in the modern world. Moscow, Russia: Peoples' Friendship University of Russia.

Sala, G., Foley J. P., \& Gobet, F. (2017). The effects of chess instruction on pupils' cognitive and academic skills: State of the art and theoretical challenges. Frontiers in Psychology, 8. https:// doi.org/10.3389/fpsyg.2017.00238.

Sala, G., \& Gobet, F. (2016). Do the benefits of chess instruction transfer to academic and cognitive skills? A meta-analysis. Educational Research Review, 18, 46-57. https://doi.org/10.1016/j. edurev.2016.02.002.

Sala, G., \& Gobet F. (2017). Does chess instruction improve mathematical problem-solving ability? Two experimental studies with an active control group. Learning \& Behavior, 45(4), 414-421. https:// doi.org/10.3758/s13420-017-0280-3.

Smirnov, E., Sekovanov, V., \& Mironkin D. (2014). Multi-Stage Mathematic-Information Tasks as a Means to Develop Pupils' Creativity in Profile Mathematical Classes. Yaroslavl Pedagogical Bulletin, 1, 124-129.

Sukhin, I. (2012). School Subject "Chess" as a tool of developing thinking: History, methodology, scientific research and experience of implementation. Saarbrücken, Germany: Lambert Academic Publishing. 
Svetlana N. DVORYATKINA, Vladimir S. KARAPETYAN, Alla M. DALLAKYAN, Svetlana A. ROZANOVA, Eugeny I. SMIRNOV. Synergetic effects manifestation by founding complexes deployment of mathematical tasks on the chessboard

PROBLEMS

OF EDUCATION

IN THE $21^{\text {st }}$ CENTURY

Vol. 77, No. 1, 2019

21

Received: October 18, 2018

Accepted: January 10, 2019

Svetlana N. Dvoryatkina

Doctor of Pedagogical Sciences, Professor, Head of the Department of Mathematics and Methods of Teaching, Federal State Budgetary Educational Institution of Higher Education "Bunin Yelets State University", Yelets, Russia.

E-mail: sobdvor@yelets.lipetsk.ru

Vladimir S. Karapetyan Doctor of Psychological Sciences, Professor, Head of the Department of Preschool Pedagogy and Methods, Armenian State Pedagogical University named after Khachatur Abovyan, Yerevan, Republic of Armenia.

E-mail: vskarapetyan@mail.ru

Alla M. Dallakyan

$\mathrm{PhD}$, Assistant Professor of the Department of Pre-school Pedagogy and Methods, Armenian State Pedagogical University named after Khachatur Abovyan,

Yerevan, Republic of Armenia.

E-mail: alla.dallakyan@gmail.com

Svetlana A. Rozanova Doctor of Pedagogical Sciences, Professor of the Department of Higher Mathematics, Federal State Budgetary Educational Institution of Higher Education "Russian Technological University", Moscow, Russia.

E-mail: srozanova@mail.ru

Eugeny I. Smirnov

Doctor of Pedagogical Sciences, Professor, Head of the Department of Mathematical Analysis, Yaroslavl State Pedagogical University K.D. Ushinsky, Yaroslavl, Russia.

E-mail: smiei@mail.ru 